\title{
Mediating Effects of Self-esteem in the Effect of Depression on Physical Health of Divorced and Married Elderly
}

\author{
Yun-Jeong Kim \\ Department of Health, Counselling and Welfare, Hanseo University, Seosan-Si, Republic of Korea
}

Received September 14, 2021; Revised December 6, 2021; Accepted December 27, 2021

\begin{abstract}
Cite This Paper in the following Citation Styles
(a): [1] Yun-Jeong Kim, "Mediating Effects of Self-esteem in the Effect of Depression on Physical Health of Divorced and Married Elderly," Universal Journal of Public Health, Vol. 9, No. 6, pp. 499 - 506, 2021. DOI: 10.13189/ujph.2021.090619.

(b): Yun-Jeong Kim (2021). Mediating Effects of Self-esteem in the Effect of Depression on Physical Health of Divorced and Married Elderly. Universal Journal of Public Health, 9(6), 499 - 506. DOI: 10.13189/ujph.2021.090619.
\end{abstract}

Copyright $\odot 2021$ by authors, all rights reserved. Authors agree that this article remains permanently open access under the terms of the Creative Commons Attribution License 4.0 International License

\begin{abstract}
Divorce in Korean society is a phenomenon that occurs in the early years of marriage or in old age, and the increase in divorce in the old age has been a distinct phenomenon in the last 10 years. The purpose of this study was to identify the structural connection between depression, health status, and self-esteem, focusing on the difference between divorced elderly and married elderly. For this purpose, data of the 14th Korea Welfare Panel were used in this study. In this study, only divorced and married elderly people aged 65 and over were selected and used for analysis. 3,076 people were subjects (177 divorced and 2,899 married elderly). Frequency analysis, reliability analysis, correlation analysis, and t-test were performed using SPSS Win version 21.0 and SPSS MACRO No. 4 model was used to determine the mediating effect of self-esteem in the effect of depression of divorced and married elderly on their physical health. The main results are summarized. First, divorced elderly had higher depression and lower self-esteem than married elderly. However, there was no difference in physical health between divorced and married elderly. Second, the mediating role of self-esteem in the effect of depression on physical health was verified in both divorced and married elderly. In other words, it was found that the negative effect of depression on physical health was alleviated by self-esteem.
\end{abstract}

Keywords Divorced Elderly, Depression, Physical Health, Self-esteem, Mediating Effect

\section{Introduction}

The number of divorces in 2020 decreased compared to that in the previous year in Korea [1]. The number of divorces per 1,000 people was 2.1 in 2020, down 0.1 from the previous year. The average divorce age was 49.4 years for men and 46.0 years for women. Divorces of those who have been married for more than 20 years, which could be called December divorces, account for $37.2 \%$ of all divorces, followed by $19.8 \%$ of divorces for those who have been married for less than 4 years. Divorce in Korean society is a phenomenon that occurs in the early days of marriage or in old age. Such increase of divorce in the old age has been a distinct phenomenon in the last 10 years. Reasons for such increase of divorce in the old age compared to that in other ages are summarized as follows. The first is the improvement of women's social and economic status. As women gain self-awareness and financial ability, the tendency to request a divorce is increasing [2]. The second is the change in values of marriage. Most divorces in old age begin with conflicts with a patriarchal husband and disappointed about the family [3]. Thus, divorce in old age is increasing as the permissive and open value of being able to divorce and find one's own life rather than living with patience is increasing. Thirdly, women used to have disadvantage after divorce in Korea. However, the divorce-related inequality law has been revised, making it easier to divorce now than that in the past. Fourth, because of weakening social bonds, divorce choices are becoming easier as individual free choices are increased due to weakening restrictions by family, neighbors, relatives, 
and so on [4]. Lastly, the increase in likelihood of divorce as marriage period extends due to the increase in life expectancy might also be the reason for the increase of divorce in an old age. In particular, in the case of divorce in an old age, reasons are much more specific than in those for other age groups as difficulties that will be experienced by children due to divorce are resolved to some extent since children are grown and married. Therefore, it is easy to put divorce into action. Since the instability of marriage in old age is linked to divorce behavior [4], old age divorce is driving the overall divorce rate.

Although divorce in old age is becoming more common, divorced people have a lower quality of life than married people do. This is because social prejudice by marriage breakup, economic and social emotional loss, and environmental changes such as movement of residence have negative effects on the quality of life [5]. Empirical studies have shown that divorced people are more depressed than married people [6-8]. One study has shown that elderly people with a spouse have higher self-esteem [9], although there is no difference in positive self-esteem depending on whether one has a spouse or not. However, one study has shown that negative self-esteem is higher when a spouse is present [10]. In addition, divorced people experience more physical health problems [11,12]. In other words, divorced people are less likely to take care of their health because they do not have spouses to control their unhealthy behaviors such as smoking and drinking. Also, due to the absence of a spouse, their physical health can worsen because they can be belatedly aware of a health problem or cannot get help to cope with it $[12,13]$.

As such, when depression as a typical mental health problem caused by divorce increases, self-esteem decreases and physical health status declines. This study focuses on the structural relationship between these variables. By examining related previous studies, it can be inferred that self-esteem plays a mediating role in the effect of depression in old age on physical health. To verify this reasoning, a three-step pathway (i.e., depression affects physical health and self-esteem, and self-esteem in turn affects physical health) needs to be identified.

First, it can be seen that depression has a negative effect on physical health. Higher depression is associated with lower subjective health status [14], more somatization symptoms such as headache and indigestion [15], more complaints of pain [16], and more impairment of physical function [17]. For those with poor mental health, their perceived physical health is poor and the number of actual colds is high with more severity, confirming the relationship between mental health and physical health [18]. Sbarra et al. [19] have found that divorce-related depression in divorced people can cause blood pressure problems, similar to results of another study showing that negative marital function has an indirect effect on physical health through depression [20].

Next, depression is highly correlated with self-esteem. People with high self-esteem can protect themselves from psychological difficulties. Thus, they can overcome stressful events and experience less anxiety, depression, and somatization symptoms [21].

Finally, self-esteem is related to physical health. In other words, the lower the self-esteem, the more the negative assessment of one's physical health [22] and the lower the subjective health status [23]. The lower the self-esteem, the more the physical illness and the poor the cardiopulmonary function [24], and the slower the recovery [25]. This is because when self-esteem decreases, belief in one's ability to control the surrounding environment and coping ability also decreases, thus negatively affecting the state of physical health by not taking actions that are conducive to health or taking risky actions such as drinking [26].

Therefore, self-esteem is expected to play a mediating role in the influence of the elderly's depression on their physical health. Also, considering that there are differences in depression, physical health, and self-esteem between married and divorced people, the mediating role of self-esteem is predicted to be different between divorced elderly and married elderly. However, such research has not been reported yet.

Therefore, the purpose of this study was to identify the structural connection between depression, health status, and self-esteem, focusing on the difference between divorced elderly and married elderly. This study is performed to address the following questions: 1) is there a difference in depression, self-esteem, and physical health between divorced elderly and married elderly?, 2) what is the correlation between depression, self-esteem, and physical health of divorced elderly and married elderly? and 3) does self-esteem play a mediating role in the effect of depression of divorced elderly and married elderly on their physical health?

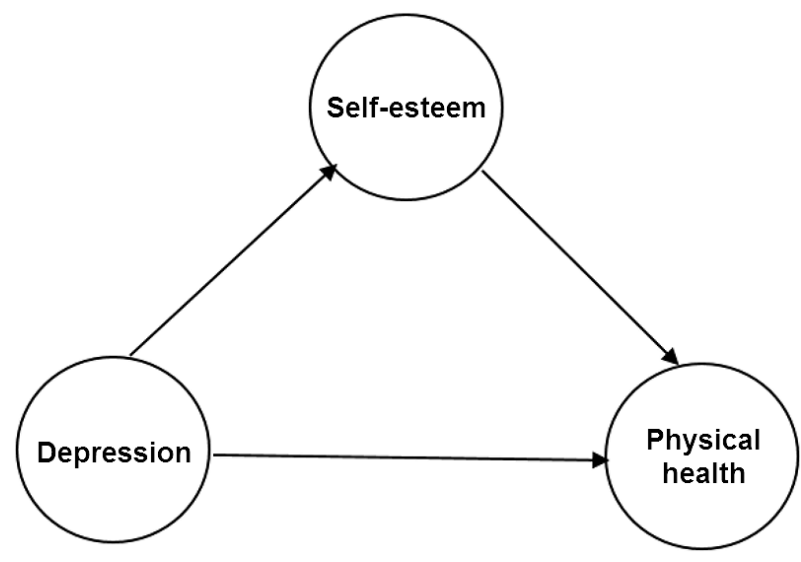

Figure 1. Research Model

\section{Materials and Methods}

\subsection{Research Model}

In this study, based on previous studies, the research model shown in Figure 1 will be verified. In Figure 1, depression affects subjective health status and self-esteem. Self-esteem also affects subjective health status. Also, 
self-esteem is a parameter, and it will play a role as a parameter in the effect of depression on physical health.

\subsection{Research Subjects}

In this study, data of the 14th Korea Welfare Panel [27] published in 2020 were used. The Korean Welfare Panel selects 7,000 households as a longitudinal survey of the entire country including Jeju Island and conducts an annual survey. The Korean Welfare Panel is also a survey that secures national representation by including various types of household types, including rural areas in towns and villages. In this study, only divorced and married elderly people aged 65 and over were selected and used for analysis. 3,076 people were subjects of this study.

\subsection{Measuring Tools}

Depression was used by translating CES-D (Center for Epidemiologic Studies- Depression Scale) [28], a question about the state of the past one week at the time of the survey. It is a scale with 11 questions, including "no appetite, sleep fitfully, loneliness, and sadness". Each question is evaluated with a 4-point Likert scale ("extremely rare" (1 point) to "mostly" (4 points). In this study, two items of 'I get along relatively well' and 'I live without complaints' were reverse-coded. The average value of the 11 items was used for analysis, with higher score indicating higher depression. Regarding the reliability of the scale, the Cronbach's alpha value was 0.917 .

Self-esteem was based on Rosenberg [29]'s self-esteem scale with 10 questions evaluated with a 4-point Likert-scale ( $1=$ not at all, $4=$ very yes). 5 items were reverse-coded, and the average value of 10 items was used for analysis. The higher the score, the higher the self-esteem. Regarding the reliability of the scale, the Cronbach's alpha value was 0.842 .

Physical health uses a single question about the subjective health status of elderly evaluated with a five-point Likert scale. This is a question that is supposed to subjectively answer the question 'How is your health compared to your peers?' The higher the score, the better the subjective health condition.

\subsection{Characteristics of Research Subjects}

Among the elderly aged 65 years or older who responded to the 14th Korea Welfare Panel [27], the total number of divorced was 177 , with $60.8 \%$ aged 60 to $69,31.8 \%$ aged 70 to 79 , and $7.3 \%$ aged 80 or older. As for their academic background, $40.6 \%$ of those had graduated from elementary school or lower, followed by $32.9 \%$ of those who had graduated from high school or higher, and $26.6 \%$ of those who had graduated from middle school. Religious and non-religious elderly showed the same rate at $50.0 \%$.

Of 2,899 married elderly, males accounted for $53.2 \%$ and females accounted for $46.8 \%$. As for the age of married elderly, 70-79 years old was the most common at $43.0 \%$, followed by 60-69 years old at $39.9 \%$ and 80 years old or older at $17.1 \%$. In terms of educational background, those who had graduated from elementary school or lower were the most (44.9\%), followed by those who graduated from high school or higher (32.6\%) and middle school graduation $(22.5 \%)$. Among married elderly, $55.8 \%$ had a religion while $44.2 \%$ had no religion.

\subsection{Analysis Method}

To achieve the purpose of this study, SPSS Win version 21.0 and SPSS MACRO were used. Frequency analysis, reliability analysis, correlation analysis, and t-test were performed using SPSS Win version 21.0. SPSS MACRO No. 4 model was used to determine the mediating effect of self-esteem in the effect of depression of divorced and married elderly on their physical health. Bootstrap was used to verify the mediating effect. At the time of verification, the number of bootstrap samples was designated as 5,000 and the confidence interval was set to be $95 \%$.

\section{Results}

\subsection{Differences in Variables between Divorced Elderly and Married Elderly}

Differences in depression, self-esteem, and subjective physical health between divorced elderly and married elderly in Korea were analyzed using t-test (Table 1). As shown in Table 1, differences in depression and self-esteem between divorced elderly and married elderly were significant. Divorced elderly had higher depression $(t=4.693, \mathrm{p}<.001)$ but lower self-esteem $(t=-4.673, p<.001)$ than married elderly. However, the difference in subjective physical health between divorced elderly and married elderly was not statistically significant.

Table 1. Differences in variables between Divorced Elderly and Married Elderly Koreans $(\mathrm{N}=3,076)$

\begin{tabular}{|c|c|c|c|c|c|}
\hline & & $\mathbf{N}$ & M & SD & $\mathbf{t}$ \\
\hline \multirow{2}{*}{ Depression } & $\begin{array}{c}\text { Divorced } \\
\text { elderly }\end{array}$ & 177 & 1.62 & .605 & \multirow{2}{*}{$4.693^{* * *}$} \\
\hline & $\begin{array}{c}\text { Married } \\
\text { elderly }\end{array}$ & 2,899 & 1.40 & .446 & \\
\hline \multirow{2}{*}{ Self-esteem } & $\begin{array}{c}\text { Divorced } \\
\text { elderly }\end{array}$ & 177 & 2.80 & .504 & \multirow{2}{*}{$-4.673^{* * * *}$} \\
\hline & $\begin{array}{c}\text { Married } \\
\text { elderly }\end{array}$ & 2,899 & 2.98 & .425 & \\
\hline \multirow{2}{*}{$\begin{array}{c}\text { Physical } \\
\text { health }\end{array}$} & $\begin{array}{c}\text { Divorced } \\
\text { elderly }\end{array}$ & 181 & 2.76 & .941 & \multirow{2}{*}{.136} \\
\hline & $\begin{array}{l}\text { Married } \\
\text { elderly }\end{array}$ & 3,122 & 2.75 & .893 & \\
\hline
\end{tabular}

${ }^{* * * *} p<.001$.

Since differences in depression and self-esteem between the divorced and married elderly were statistically significant, 
there might be a difference in the path of the elderly's depression through self-esteem to physical health between divorced elderly and married elderly. Therefore, in subsequent analysis, the divorced elderly and the married elderly were analyzed separately.

\subsection{Correlations among Depression, Physical Health, and Self-esteem of Divorced Elderly and Married Elderly}

In the case of divorced elderly, correlations among depression, self-esteem, and physical health were all statistically significant (Table 2). The higher the depression, the lower the self-esteem $(r=-.543, p<.001)$, the lower the physical health $(\mathrm{r}=-.391, \mathrm{p}<.001)$. The higher the self-esteem, the higher the physical health $(\mathrm{r}=.418, \mathrm{p}<.001)$. The same was true for married elderly. That is, the higher the depression, the lower the self-esteem $(r=-.429, p<.001)$ and the lower the physical health $(r=-.374, p<.001)$. The higher the self-esteem, the higher the physical health $(\mathrm{r}=.318, \mathrm{p}$ $<.001$ ). Correlation coefficient ranged from 0.391 to 0.543 for divorced elderly and from 0.318 to 0.429 for the married elderly. There was no risk of multicollinearity between variables.

\subsection{Mediating Effect of Self-esteem on Effects of Depression on Physical Health in Divorced Elderly and Married Elderly}

To analyze the mediating effect of self-esteem on the effect of depression on physical health, Hayes [30]'s SPSS MACRO 3.5 version 4 model was applied. The significance of the mediating effect (indirect effect) was analyzed according to the suggestion of Zhao et al. [31] and Rucker et al. [32].

\subsubsection{Divorced elderly}

Depression of the divorced elderly had a negative effect on physical health $(\beta=-.600, p<.001)$. In other words, the higher the depression, the worse the physical health (Figure
2). After analyzing the path of depression on physical health through self-respect, the mediating effect of self-respect was found to be significant as shown in Figure 3, Table 3, and Table 4. Specifically, the higher the depression, the lower the self-esteem $(\beta=-.453, p<.001)$. The higher the self-esteem, the better the physical health $(\beta=.538, p<.001)$. Total effect of depression on physical health decreased from 0.600 to 0.356 in the self-esteem added model. In addition, as shown in Table 4, in the path of Depression $\rightarrow$ Self-esteem $\rightarrow$ Physical health, the bootstrap value was -0.244 . There was no ' 0 ' between upper and lower limits $(-.482 \sim-.086)$, indicating that the indirect effect was significant. Therefore, it can be concluded that self-esteem plays a mediating role in the effect of depression on physical health of divorced elderly Koreans.

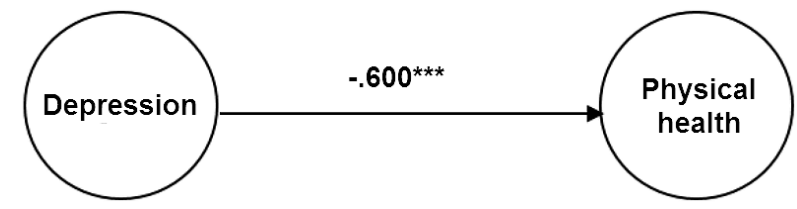

Figure 2. Effect of Depression on Physical Health of Divorced Elderly Koreans

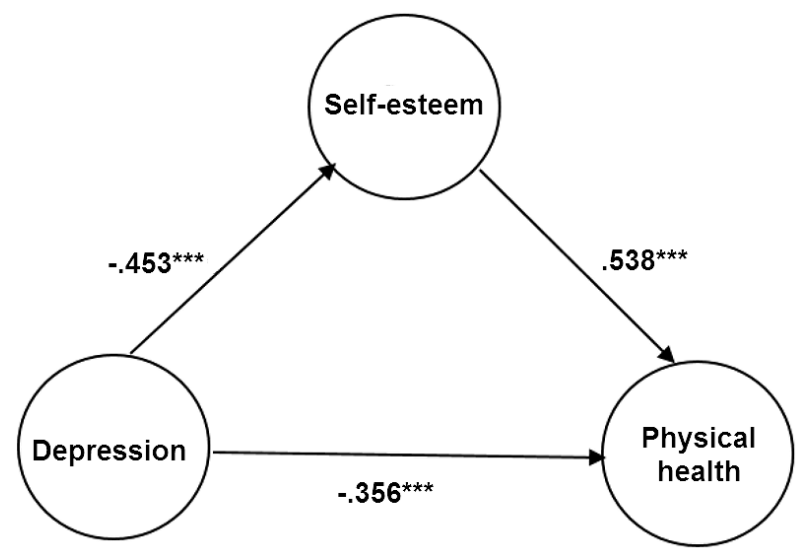

Figure 3. Mediating Effect of Self-esteem on the Relationship between Depression and Physical Health of Divorced Elderly

Table 2. Correlation between Variables $(\mathrm{N}=3,076)$

\begin{tabular}{|c|c|c|c|c|}
\hline & & Depression & Self-esteem & Physical health \\
\hline \multirow{3}{*}{$\begin{array}{l}\text { Divorced } \\
(\mathrm{n}=177)\end{array}$} & Depression & & & \\
\hline & Self-esteem & $-.543^{* * *}$ & & \\
\hline & Physical health & $-.391^{* * * *}$ & $.418^{* * * *}$ & \\
\hline \multirow{3}{*}{$\begin{array}{c}\text { Married } \\
(\mathrm{n}=2,899)\end{array}$} & Depression & & & \\
\hline & Self-esteem & $-.429^{* * * *}$ & & \\
\hline & Physical health & $-.374^{* * *}$ & $.318^{* * * *}$ & \\
\hline
\end{tabular}


Table 3. Mediating Effect of Self-esteem on the Relationship between Depression and Physical Health of Divorced Elderly $(\mathrm{N}=177)$

\begin{tabular}{|c|c|c|c|c|c|c|c|c|c|}
\hline \multirow{2}{*}{ Dependent } & \multirow{2}{*}{ Independent } & \multirow{2}{*}{ Coeffect } & \multirow{2}{*}{ SE } & \multirow{2}{*}{$\mathbf{t}$} & \multirow{2}{*}{$\mathbf{p}$} & \multicolumn{2}{|c|}{$95 \%$ confidence interval } & \multirow{2}{*}{$\mathbf{F}$} & \multirow{2}{*}{$\mathbf{R}^{2}$} \\
\hline & & & & & & LLCI & ULCI & & \\
\hline \multirow{2}{*}{$\begin{array}{l}\text { Physical } \\
\text { health }\end{array}$} & Constant & 3.755 & .184 & 20.362 & .000 & 3.391 & 4.119 & \multirow{2}{*}{31.491} & \multirow{2}{*}{.153} \\
\hline & Depression & -.600 & .107 & -5.612 & .000 & -.811 & -.389 & & \\
\hline \multirow{2}{*}{ Self-esteem } & Constant & 3.535 & .091 & 38.705 & .000 & 3.354 & 3.715 & \multirow{2}{*}{73.244} & \multirow{2}{*}{.295} \\
\hline & Depression & -.453 & .053 & -8.558 & .000 & -.558 & -.349 & & \\
\hline \multirow{3}{*}{$\begin{array}{c}\text { Physical } \\
\text { health }\end{array}$} & Constant & 1.852 & .551 & 3.361 & .001 & .764 & 2.940 & \multirow{3}{*}{23.513} & \multirow{3}{*}{.213} \\
\hline & Depression & -.356 & .123 & -2.892 & .004 & -.600 & -.113 & & \\
\hline & Self-esteem & .538 & .148 & 3.648 & .000 & .247 & .830 & & \\
\hline
\end{tabular}

Table 4. Verification of Indirect Effect of Self-esteem of Divorced Elderly (N=177)

\begin{tabular}{|c|c|c|c|c|}
\hline & Effect & Boot SE & \multicolumn{2}{|c|}{ BC 95.0\% CI } \\
\hline Depression $\rightarrow$ Self-esteem $\rightarrow$ Physical health & -.244 & .094 & -.482 & -.086 \\
\hline
\end{tabular}

Table 5. Mediating Effect of Self-esteem on the Relationship between Depression and physical health of married elderly Koreans $(\mathrm{N}=2,899)$

\begin{tabular}{|c|c|c|c|c|c|c|c|c|c|}
\hline \multirow{2}{*}{ Dependent } & \multirow{2}{*}{ Independent } & \multirow{2}{*}{ Coeffect } & \multirow{2}{*}{ SE } & \multirow{2}{*}{$\mathbf{t}$} & \multirow{2}{*}{$\mathbf{p}$} & \multicolumn{2}{|c|}{$\mathbf{9 5 \%}$ confidence interval } & \multirow{2}{*}{$\mathbf{F}$} & \multirow{2}{*}{$\mathbf{R}^{2}$} \\
\hline & & & & & & LLCI & ULCI & & \\
\hline \multirow{2}{*}{$\begin{array}{c}\text { Physical } \\
\text { health }\end{array}$} & Constant & 3.824 & .049 & 78.137 & .000 & 3.728 & 3.920 & \multirow{2}{*}{471.980} & \multirow{2}{*}{.140} \\
\hline & Depression & -.724 & .033 & -21.725 & .000 & -.789 & -.659 & & \\
\hline \multirow{2}{*}{ Self-esteem } & Constant & 3.555 & .024 & 151.369 & .000 & 3.509 & 3.601 & \multirow{2}{*}{652.928} & \multirow{2}{*}{.184} \\
\hline & Depression & -.409 & .016 & -25.553 & .000 & -.440 & -.377 & & \\
\hline \multirow{3}{*}{$\begin{array}{c}\text { Physical } \\
\text { health }\end{array}$} & Constant & 2.430 & .144 & 16.935 & .000 & 2.149 & 2.711 & \multirow{3}{*}{297.731} & \multirow{3}{*}{.171} \\
\hline & Depression & -.564 & .036 & -15.557 & .000 & -.635 & -.493 & & \\
\hline & Self-esteem & .391 & .038 & 10.311 & .000 & .318 & .467 & & \\
\hline
\end{tabular}

\subsubsection{Married elderly}

Depression of married elderly negatively affected their physical health $(\beta=-.724, p<.001)$. In other words, the higher the depression, the worse the physical health (Figure 4). After analyzing the path of depression on physical health through self-respect, the mediating effect of self-respect was found to be significant as shown in Figure 5, Table 5, and Table 6. Specifically, the higher the depression, the lower the self-esteem $(\beta=-.409, p<.001)$. The higher the self-esteem, the better the physical health $(\beta=.391, \mathrm{p}<.001)$. The total effect of depression on physical health decreased from 0.724 to 0.564 in the self-esteem added model. In addition, as shown in Table 4, in the path of Depression $\rightarrow$ Self-esteem $\rightarrow$ Physical health, the bootstrap value was -0.160 . There was no ' 0 ' between upper and lower limits (-.196 to -.128). It can be said that the indirect effect is significant. Therefore, it can be concluded that self-esteem plays a mediating role in the effect of depression on physical health of married elderly Koreans.

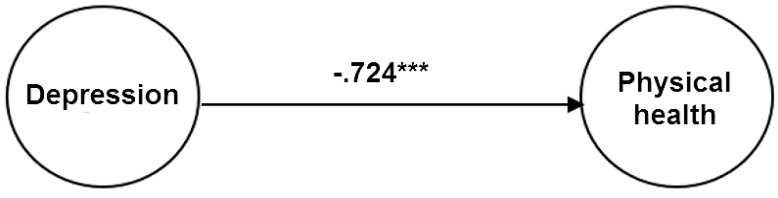

Figure 4. Effect of Depression on Physical Health of Married Elderly

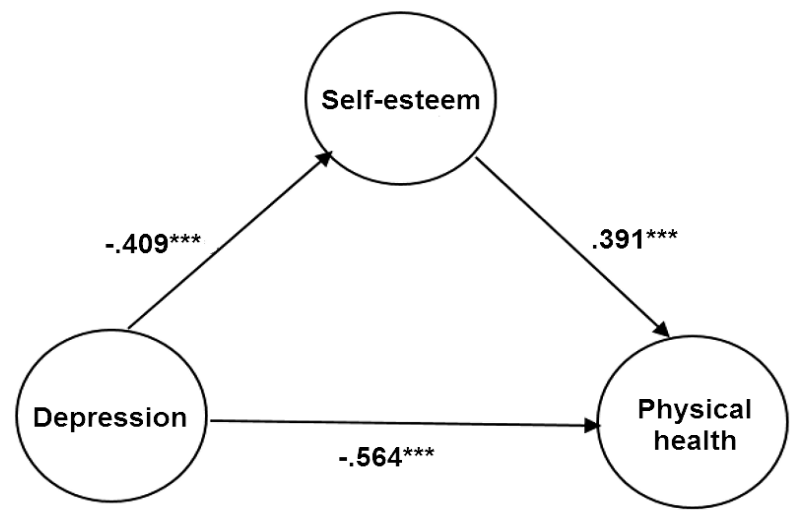

Figure 5. Mediating Effect of Self-esteem on the Relationship between Depression and Physical Health of Married Elderly 
Table 6. Verification of Indirect Effect of Self-esteem of Married elderly $(\mathrm{N}=2,899)$

\begin{tabular}{|c|c|c|c|c|}
\hline & Effect & Boot SE & \multicolumn{2}{|c|}{ BC 95.0\% CI } \\
\hline Depression $\rightarrow$ Self-esteem $\rightarrow$ Physical health & -.160 & .017 & -.196 & -.128 \\
\hline
\end{tabular}

\section{Discussion}

The purpose of this study was to identify the structural connection among depression, health status, and self-esteem, focusing on the difference between divorced elderly and married elderly. For this purpose, data of the 14th Korea Welfare Panel [27] were used in this study. Research subjects were 177 divorced and 2,899 married elderly Koreans. Main results are summarized and discussed as follows.

First, divorced elderly had higher depression and lower self-esteem than married elderly, consistent with preceding research studies [6-8]. This might be because divorce itself is a stress. In addition, living as a divorced person or single parent can be considered as a secondary stress as it has a negative effect on mental health such as depression [26].

Next, the fact that the divorced elderly had lower self-esteem compared to the married elderly was in the same context as preceding research studies [9-10]. The decrease in self-esteem due to divorce can be explained in the following ways. First, self-esteem is related to positive or negative evaluation of oneself. It is a concept of how much you value yourself [29]. Self-esteem is the basis of human mental and social health. It is the basis for maintaining a qualitative life. This self-esteem is the result of accumulating life experiences that are important, such as the quality of intimate relationships [33]. It can be interpreted that self-esteem might have decreased due to a worsening relationship between the spouse and the family, one of the most intimate relationships, due to divorce. Second, self-esteem is a reflection of other people's evaluations. If someone important to you ignores or does not appreciate your value, you will not appreciate your worth [34]. In other words, it is highly likely if one ignored by his/his spouse, who was an important person throughout his life due to the divorce, he/she is highly likely to feel hurtful, leading to a low self-esteem after divorce.

However, there was no difference in physical health between divorced and married elderlies. This result is a different from results of preceding studies [11-12] showing that divorced people have a higher mortality rate and poorer physical health than married ones. In other words, it seems that the social control function in marriage does not work well in old age. Social control means that the love, interest, and responsibility of a family formed through marriage, such as a spouse or child, are controlled not only by yourself, but also by taking a stable life style and reducing risky behaviors [35].

Second, the mediating role of self-esteem in the effect of depression on physical health was verified in both divorced and married elderlies. In other words, it was found that the negative effect of depression on physical health was alleviated by self-esteem. Therefore, efforts to improve self-esteem are needed to alleviate the deterioration of physical health due to depression that appears in old age. When people get old, their self-esteem tends to decrease due to sensory and cognitive loss, loss of family and friends, and loss of roles. When one's self-esteem decreases, one may lose the desire to live by thinking oneself as worthless [29]. Therefore, it is important to find a way to improve the self-esteem of the elderly. Above all, when one's self-esteem is low, one might feel incompetent, which in turn causes anxiety and increases one's sensitivity to stress. Thus, efforts should be made to improve self-esteem of the elderly.

In particular, considering that the divorced elderly had lower self-esteem than the married elderly, a self-esteem improvement program for the divorced elderly would be needed first. Fortunately, self-esteem continues to change. Above all, self-esteem in adulthood can be changed through experiences of various social interactions. Thus, a variety of ways for divorced elderly to participate in social activities are required. Through social participation, they can receive emotional support and satisfy their desire for belonging. This emotional satisfaction can help individuals to be less responsive to stress and thus improve their physical health [11].

\section{Conclusions}

The purpose of this study was to identify the mediating effect of self-esteem in the effect of depression on physical health of divorced and married Elderly.

First, the divorced elderly had higher depression and lower self-esteem than the married elderly. But, there was no difference in physical health between the divorced and the married elderly. Second, it was found that the negative effects of depression on physical health were alleviated by self-esteem. Therefore, efforts to improve self-esteem are needed to alleviate the deterioration of physical health due to depression that appears in old age. In particular, considering that the divorced elderly have lower self-esteem than the married elderly, a self-esteem improvement program for divorced elderly is needed first.

As such, this study is meaningful in that reveals that depression of divorced and married elderly Koreas can affect their physical health through self-esteem. However, since divorce and marital status in old age were limited to the time of the data survey, making it impossible to control the number of divorces, divorce period, or remarriage. Thus, caution is needed when generalizing findings of this study to all divorced and married elderlies. 


\section{REFERENCES}

[1] Statistics Korea, 2020 Marriage and Divorce Statistics, https://kostat.go.kr/portal/korea/kor_nw/1/1/index.board?b mode $=$ read\&aSeq=388686, 2021 (accessed Feb.11, 2021).

[2] Lichtenstein, B., Lucke, J., Loxton, D., "Women and Divorce: Financial Coping from Midlife to Older Age", Journal of Women \& Aging, Vol.33, No.5, pp.1-18, 2021, DOI: $10.1080 / 08952841.2021 .1935552$

[3] Ding, D., Gale, J., Bauman, A., Phongsavan, P., \& Nguyen, B., Effects of Divorce and Widowhood on Subsequent Health Behaviors and Outcomes in a Sample of Middle-aged and Older Australian adults. Scientific Reports, Vol.11, No.1, pp.1-10, 2021, https://www.nature.com/articles/s41598-021-93210-y

[4] Ryu, S.H., Jung, M.J., "A Study on Decision Making Processes of Twilight Divorce: Grounded Theory", Journal of Korean Home Management Association. Vol.36, No.2, pp. 54-71, 2017, DOI: 10.7466/JKHMA.2018.36.2.54

[5] Han, G. H., Choi, H. J., "The Influence of Daily Social Interaction and Physical Activity on Daily Happiness of Korean Urban Older Adults", Journal of the Korean Gerontological Society, Vol.38, No.4, pp.1083-1105, 2018, DOI: $10.31888 / J K G S .2018 .38 .4 .1083$

[6] Canady, R. B., \& Broman, C., "Marital Disruption and Health: Investigating the Role of Divorce in Differential Outcomes", Sociological Focus, Vol.36, No.3, pp.241-255, 2003, DOI: 10.1080/00380237.2003.10570726

[7] Lee, M. A., "Depression and Gender Differences in the Elderly According to Marital Status", Korean Journal of Sociology, Vol.44, No.4, pp.32-62, 2010, http://www.dbpia.co.kr.ssl.library.hanseo.ac.kr:8000/pdf/p dfView.do?nodeId=NODE01548782

[8] Kim, Y. J., "Panel analysis on the changes in the quality of life of the divorced elderly", Elementary Education Online, Vol.20, No.3, pp.1328-34, 2021, DOI: 10.17051/ilkonline.2021.03.112

[9] Kim, H., Moon, H., \& Chang, H., "Self-esteem Changes among the Adults across the Lifespan: Examining the Predictors of the Change", Korean Journal of Social Welfare, Vol.67, No.1, pp.83-107, 2015, https://www.koreascience.or.kr/article/JAKO20150995711 5358.page

[10] Yoo, C. M., "The 10-year Change Process of Dual Self-esteem: Focusing on Early Adulthood, Middle Age, and Old Age", Health and Social Welfare Review, Vol.38, No.3, pp.7-44, 2018, DOI: 10.15709/hswr.2018.38.3.7

[11] Williams, K., Umberson, D., "Marital Status, Marital Tnsitions, and Health: A Gendered Life Course Perspective", Journal of Health and Social behavior, Vol.45, No.1, pp.81-98, 2004, DOI: 10.1177/002214650404500106

[12] Umberson, D., Liu, H., Powers, D., "Marital Status, Marital Transitions, and Body Weight", Journal of Health and Social Behavior, Vol.50, No.3, pp.327-343, 2009, DOI: $10.1177 / 002214650905000306$
[13] Shor, E., Roelfs, D. J., Bugyi, P., \& Schwartz, J. E., "Meta-analysis of Marital Dissolution and Mortality: Reevaluating the Intersection of Gender and Age", Social science \& medicine, Vol.75, No.1, pp.46-59, 2012, DOI: 10.1016/j.socscimed.2012.03.010

[14] Kim, J. M., Lee. J.A., "Depression and Health Status in the Elderly", Journal of the Korean Gerontological Society, Vol.30, No.4, pp.1311-1327, 2010, http://scholar.dkyobobook.co.kr.library.hanseo.ac.kr:8000/ searchDetail.laf?barcode $=4010023766728$

[15] Lee, M. J., Lim, C. K., Ryu, J. Y., "The Effect of the Stress, Anxiety and Depression on Somatization: Focused on Specialized Vocational High School Students", The Journal Korean Welfare Administration Research, Vol.30, No.1, pp.109-33, 2014, http://kiss18.kstudy.com.ssl.library. hanseo.ac.kr:8000/kiss9/download_viewer.asp

[16] Jung, Y. M., "Health Status and Associated Factors of Depression According to Depression in Elderly Women", Journal of the Korean Gerontological Society, Vol.27, No.1, pp.71-86, 2007, http://scholar.dkyobobook.co.kr. library.hanseo.ac.kr:8000/searchDetail.laf?barcode $=40100$ 23766728

[17] Gang, M. H. Yoon, S.Y., Kwon, M. J., “Activity of Daily Living, Interpersonal Relationship, Depression and Health-related Quality of Life in Patients with Hand Microsurgery", Korean Journal of Occupational Health Nursing Vol.20, No.3, pp.289-298, 2011, DOI: 10.5807/kjohn.2011.20.3.289

[18] Kim, H. J., Ko. Y. G., "The Relationship Between Mental Health and General Physical Health", Korean Journal of Health Psychology, Vol.21, No.4, pp.815-828, 2016, DOI: 10.17315/kjhp.2016.21.4.008

[19] Sbarra, D. A., Law, R. W., Portley, R. M., "Divorce and Death: A Meta-analysis and Research Agenda for Clinical, Social, and Health Psychology", Perspectives on Psychological Science, Vol.6, No.5, pp.454-474, 2011, DOI: $10.1177 / 1745691611414724$

[20] Kiecolt-Glaser, J.K., Newton, T., Cacioppo, J.T., MacCallum, R.C., Glaser, R., Malarkey, W.B., "Women and divorce: financial coping from midlife to older age. Marital Conflict and Endocrine Function: Are Men Really More Physiologically Affected than Women?", Journal of Consulting and Clinical Psychology, Vol.64, No.2, pp.324-32, 1996, DOI: 10.1037/0022-006x.64.2.324

[21] Whisman, M. A., \& Kwon, P., "Life Stress and Dysphoria: The Role of Self-esteem and Hopelessness", Journal of Personality and Social Psychology, Vol.65, No.5, pp.1054-1060, 1993, DOI: 10.1037/0022-3514.65.5.1054

[22] Kim, G. H., Kim,H. S., Park. G. S., "The Effects of Family Function, Self-esteem, and Loneliness on Subjective Health Status in Middle-aged Women", Journal of Korean Academy of Adult Nursing, Vol.17, No.2, pp.200-207, 2005, UCI: G704-000678.2005.17.2.001

[23] Hudd, S. S., Dumlao, J., Erdmann-Sager, D., Murray, D., Phan, E., Soukas, N., Yokozuka, N., "Stress at College: Effects on Health Habits, Health Status and Self-esteem", College Student Journal, Vol.34, No.2, pp. 217-228, 2000, https://eds.b.ebscohost.com/eds/detail/detail?vid=0\&sid=8 66c06d8-6034-4bca-8590-eb03d250f60e\%40sessionmgr10 3\&bdata $=$ Jmxhbmc9a28mc210ZT11ZHMtbGl2ZQ\%3d\%3 $\mathrm{d} \# \mathrm{AN}=3452554 \& \mathrm{db}=\mathrm{asn}$ 
[24] Trzesniewski, K. H., Donnellan, M. B., Moffitt, T. E., Robins, R. W., Poulton, R., Caspi, A., "Low Self-Esteem During Adolescence Predicts Poor Health, Criminal Behavior, and Limited Economic Prospects During Adulthood", Developmental Psychology, Vol.42, No.2, pp.381-390, 2006, DOI: 10.1037/0012-1649.42.2.381

[25] Chang, A. M., Mackenzie, A. E., "State Self-esteem Following Stoke", Stroke, Vol.29, No.11, pp.2325-2328, 1998, DOI: 10.1161/01.STR.29.11.2325

[26] Jang, E.K., Choi, H.J., "Association between Divorce and Physical Health in Middle Age: Gender Difference in the Mediating Effect of Family/Social Relationship Satisfaction". Journal of the Korean Family Relations, Vol.24, No.1, pp.23-43, 2019, DOI: 10.21321/jfr.24.1.23

[27] Korea Welfare Pannel Study. Data \& Survey, https://www.koweps.re.kr:442/data/data /list.do (accessed Jun. 8, 2021).

[28] Kohout, F.J., Berkman. L.F., Evans, D.A., Cornoni-Huntley, J., "Two Shorter Forms of the CES-D Depression Symptoms Index", Journal of Aging and Health, Vol.5, No.2, pp.179-193, 1993, DOI: 10.1177/089826439300500 202

[29] Rosenberg, M., "Rosenberg Self-esteem Scale (RSE). Acceptance and Commitment Therapy. Measures Package", Vol.61, No.52, p.18, 1965, http://www.integrativehealthpa rtners.org/downloads/ACTmeasures.pdf\#page $=61$

[30] Hayes, A. F., "Partial, Conditional, and Moderated
Mediation: Quantification, Inference, and Interpretation", Communication Monographs, Vol.85, No.1, pp.4-40, 2018, DOI: 10.1080/03637751.2017.1352100

[31] Zhao, X., Lynch, J. G., Chen, Q., "Reconsidering Baron and Keny: Myths and Truths about Mediation Analysis", Journal of Consumer Research, Vol.37, No.2, pp.197-206, 2010, DOI: $10.1086 / 651257$

[32] Rucker, D. D., Preacher, K. J., Tormala, Z. L., Pety, R. E., "Mediation Analysis in Social Psychology: Current Practices and New Recommendations", Social and Personality Psychology Compas, Vol.5, No.6, pp.359-371, 2011, DOI: 10.1111/j.1751-9004.2011.00355.x

[33] Baumeister, R. F., Campbell, J. D., Krueger, J. I., Vohs, K. D., "Does High Self-esteem Cause Better Performance, Interpersonal Success, Happiness, or Healthier Lifestyles?", Psychological Science in the Public Interest, Vol.4, No.1, pp.1-44, 2003, DOI: 10.1111/1529-1006.01431

[34] Kim. D. H., "A Study on the Correlation among Family Support, Self - Esteem and Depression in Elderly", Korean Society of Gerontological Social Welfare, Vol.13, No.1, pp.113-144, 2001, http://www.dbpia.co.kr.ssl.library. hanseo.ac.kr:8000/pdf/pdfView.do?nodeId=NODE074293 59

[35] Gallagher, M., Waite, L. J., Mills, M., \& McDaniel, S. A., "The Case for Marriage: Why Married People are Happier, Healthier, and Better off Financially", Canadian Journal of Sociology, Vol.28, No.2, pp.245-248, 2003 , https://www.proquest.com/docview/220549767?pq-origsit $\mathrm{e}=\mathrm{gscholar} \&$ fromopenview $=$ true 